\title{
A CURRENT AND FUTURE AGENDA FOR COGNITIVE RESEARCH IN ORGANIZATIONS
}

\author{
AnNe Sigismund Huff \\ University of Colorado \& Cranfield School of Management
}

The study of cognition in organizational settings has expanded dramatically over the last decade in response to the interdisciplinary growth of cognitive science. The first papers to appear generated great enthusiasm for the possible applications of a cognitive perspective but, understandably, focused on cognition itself, tended to work in the absence of empirical data, were sceptical about the possibility of defining collective cognition, and introduced too many similar but somewhat inconsistent concepts. The papers in this volume illustrate how we have moved beyond those early days in several critical areas, as detailed below.

\section{Investigation of Substantive Issues}

One important sign of progress in organizational cognitive studies is our increasing capacity to address central issues in organization studies. Mark Jenkins and Gerry Johnson's study of 'Entrepreneurial intentions and outcomes' illustrates the benefits to be gained from taking a cognitive approach to substantive issues. The paper begins with the idea that management scholars have not given sufficient attention to Mintzberg's (1978) observation that outcomes are emergent and often do not correlate with a manager's initial intentions. Arguing that the capacity to achieve desired outcomes is especially important to entrepreneurial success, these authors interviewed a sample of 30 owners of independent retail stores, contrasting individuals who achieved sustained growth with those who did not. Causal maps from interview data did not show expected differences between the two groups. In an interesting and sophisticated twist, the authors then add an inductive phase to the study, re-examining the causal maps to find that those who realize entrepreneurial growth standards give a greater emphasis to internal efficiencies than competitive issues and have a greater appreciation of the business as a system. This study might be disconcerting to many strategy researchers because the data do not show a straightforward link between cognition and results, while it confirms the beliefs of many interested in organizational cognition that intuition is an important source of sensemaking.

All four papers in this special issue show a similar interest in addressing more than one audience. Thomas and Al-Maskati investigate the strategic thinking of participants in five bank training programmes; the paper is of potential interest to trainers and others in the human resource field, as well as those interested in the effect of organizational context on cognition. Hodgkinson looks at the slow

Address for reprints: Anne Sigismund Huff, College of Business and Administration and Graduate School of Business Administration, University of Colorado at Boulder, Business Building, Room 411, Campus Box 419, Boulder, Colorado, 80309-0419, USA. 
response of residential real estate agents to market turbulence in the UK as an example of cognitive inertia. The paper contributes to our knowledge of how managers view the competitive environment, discusses a key problem in achieving organizational change and outlines a solution to comparing individual assessments with a larger group. Leroy and Ramanantsoa describe both behavioural and cognitive learning in a corporate merger. Again, the paper simultaneously develops an integrated view of learning, a key issue in cognition, and discusses the problems of implementing a major strategic reorganization.

Our increasing capacity to tie cognitive work to substantive issues in this way establishes an important bridge to other management scholars. Even more important, a growing facility for linking cognition to critical organizational issues circles back to invigorate work on cognition itself. We cannot focus only on cognition; creating an organizational cognitive science requires that we ground our work in organizational issues.

\section{Empirical Evidence, Often Based on Practice}

Not only do these papers consider issues of academic interest: they also illustrate the progress made in using empirical observation. Alan Thomas and Huda AlMaskati's paper, 'Contextual influences on thinking in organizations', is particularly noteworthy for its grounded description of organizational context. This study of bank training programmes emphasizes the importance of understanding the trainees' 'hidden audience' - superiors perceived to be responsible for job advancement - when assessing participant interpretation of and behaviour in corporate education. The paper's discussion of the capacity to integrate 'a simultaneous multiplicity of selves' (Goffman, 1961) provides an interesting way of thinking about cognitive coping which can be immediately extended to analysing many other aspects of organizational life. The focus on strategic objectives throughout the organization is also a useful expansion of a perspective typically associated only with top-level managers.

The four papers in this issue are not only empirical: they also illustrate an emerging balance between theoretic and practical concerns. Early studies tended to establish the academic roots of the field. There is still considerable room for further theoretic development, as noted below, but these papers remind us that understanding organizational cognition requires that we should pay attention to the central concerns of those in organizations.

\section{Larger Sample Sizes, More Diverse and Sophisticated Methodologies}

Early empirical studies that came to my attention were based on small sample interviews and intensive case studies. Gerard Hodgkinson's paper on 'Cognitive inertia in a turbulent market' departs from that tradition by providing a longitudinal study of 114 real estate agents from 41 organizations. The substantive issue of concern is 'cognitive inertia' in assessing competitors. The paper is also of interest for its large-scale use of repertory grid methods that allow individualized but comparable responses.

In a careful pilot study, members of the industry identified a set of 21 attributes that distinguish real estate firms. Members of the sample then used the attributes to discuss 19 competitors in their environment. The questionnaire was re-administered 18 months later, after a period of significant downturn in the 
industry. As noted above, most respondents showed relatively little change in their assessment of the environment, despite considerable turmoil as evidenced by more 'objective' external measures. The analysis of the data involved threeway scaling techniques that allowed Hodgkinson to test the divergence between the aggregate 'group space' and the 'private cognitions' of individual respondents, thus operationalizing an important comparison that was the despair of early researchers (see Walsh, 1995).

All of the papers found here show an emerging sensitivity to theoretic and methodological issues. Jenkins and Johnson, for example, also compare individual and group cognition. Other attractive methodological aspects of this paper include careful definitions that allow the authors to compare intention with outcome, and a research design that moves from deductive to inductive analysis. The point is that organizational studies have become significantly more complicated and methodologically sophisticated, another indication of progress in the field.

\section{Attention to Cognition as an Emergent Phenomenon}

Frédéric Leroy and Bernard Ramanantsoa's paper, 'The cognitive and behavioural dimensions of organizational learning in a merger', illustrates a fourth desirable development in cognitive studies - a more complex appreciation of cognition itself. This paper argues that 'cognitive learning must be completed and revised by a behavioural phase of experimental learning'. Consulting as well as participant observation over six months illustrates the shifting focus of managerial attempts to make a new organizational form work. The first phase of the learning process identified by the authors was primarily cognitive, as teams met and compared practices and cultures in each company. The newly merged company then moved to a more active phase of experimentation and socialization that the authors categorize as behavioural learning. The interpretation of learning is complex, as one might expect from a field study. The authors also admirably incorporate contextual and political issues, such as the relative profitability of each unit, in analysing the course of the learning process.

This paper is especially to be praised for its clear assumption that cognitive processes are an ongoing aspect of organizational life, affecting and being affected by other emergent processes, large and small. Looking back, there is some of the same flavour in each of the papers found in this volume, which I believe is one of the most important contributions cognitive studies can make to how we can productively understand organizations.

\section{FUTURE DIRECTIONS}

To summarize the above discussion, the four papers found in this Special Issue provide several useful guidelines for further work on organizational cognition:

(1) investigate issues that link cognition to the broader agendas of organization science and simultaneously produce the insight for a truly organizational cognitive science;

(2) provide empirical evidence, including direct reports from practice, to ground further theoretic development; 
(3) design studies that utilize larger samples, longitudinal observations and otherwise expand the scope and generalizability of cognitive insights;

(4) study cognition as an emergent phenomenon, interactively linked to experience.

Further work in each of these areas will deepen understanding of organizations and cognition in organizations. But if we hope to match the impressive achievements we have seen in the last decade, I think we need to think in terms of several additional issues as well, as outlined below.

\section{More Attention to and Refinement of Core Concepts}

The cognitive agenda can only advance if we more consistently use a common vocabulary. In the absence of this effort we risk 'talking around' cognition. A case in point is the paper by Thomas and Al-Maskati, which I have already praised for giving attention to organizational context and the strategic aims of non-élites. The emphasis on hidden audiences and multiple selves found in this paper suggests interesting directions for future work. Subsequent studies will contribute more, however, if they more directly consider how attention, reasoning, memory, learning and other cognitive phenomena are channelled by context. Despite an initial disclaimer, I find more behavioural analysis than cognitive analysis in Thomas and $\mathrm{Al}$-Maskati's paper. It would be easier to connect this work with other cognitive studies if it used more of the vocabulary that is unique to cognition.

Each of the other papers found in this volume, and indeed most work on organizational cognition, including my own, would also benefit from more systematically attending to core cognitive concepts. This effort is particularly needed because many concepts used in cognitive science may need to be recalibrated for an organizational setting. Thomas and Al-Maskati convincingly document some unique aspects of adult cognition around tasks that can directly affect future livelihood. The field needs much more detail.

\section{Theoretic and Epistemic Extension of the Cognitive Agenda}

The next step is to go beyond the stage of merely using cognitive concepts from psychology and other sources and begin developing our own tools and cognitive agendas. For example, I wonder what lies beyond schema-based theory as used by Jenkins and Johnson and many others. Expanding on their suggestion that we pay closer attention to managerial intuition, we could do more to explore serendipity, inattention, forgetting, misunderstanding and other inputs to the cognitive gene pool which affect attention and action. This is only one of many areas in which expansion is needed. Organizations are intensive, ongoing social settings that are pressed to be more and more flexible. If we can go beyond schema and other received theories that refer to more controlled settings, we might have a first-mover advantage in cognitive science. But we have to move.

We should also enlarge our epistemological perspective. Rolland Paulston's (1996) new book, Social Cartography, maps a broad and challenging domain for cognitive science, in which the management studies with which I am familiar, including these four studies, are in a small 'humanist/functionalist' corner. Postmodern and other contributions are just being made; we will understand more 
about cognition as these and other perspectives gain more attention from the field.

\section{More Attention to Multiple Levels of Analysis}

I would also like future work to operate more systematically at multiple levels of analysis. By and large those working in all areas of organizational cognition (along with many working in other social sciences) have chosen to work at one or at most two levels. As we understand more about shared cognition, we can and should break the barriers we have artificially imposed. Hodgkinson's next paper on cognitive inertia, for example, might directly consider inertia at the organizational and industry level. There are broader national and international roots to inertia as well.

Further, legal, economic, technological and other aspects of context deserve more attention. Leroy and Ramanantsoa's study of learning processes is noteworthy for its indication of market and other non-cognitive influences on marriage-by-merger. Given the time one of the authors spent in the organization, more of these effects must surely be known. Although journal article page constraints significantly limit the complexity that can be offered the reader, if we develop a tradition of placing cognition in a broader context, it will be possible to tell a more complex story.

\section{Stronger Contributions to Discovering and Achieving Desired Outcomes}

Works in cognition still tend to be descriptive. Although as noted above the works in this Special Issue are to be praised for their close ties to organizations, including several consulting assignments, in the decade ahead I would like cognitive science to gain the insight to be even more assertive. Leroy and Ramanantsoa join Jenkins and Johnson, for example, in noting that several intentions from the cognitive phase of learning they observed did not survive translation into the broader organization. This is not necessarily bad news, but a worthwhile agenda for organizational cognitive studies is to gain the capacity to more actively help organizations and individuals discover workable and clever objectives, and then translate an increasingly rich version into action.

\section{A CONCLUDING GALL FOR SUSTAINED 'GLOCAL' DIALOGUE}

We have the good fortune of studying the most accessible (because it is intrinsic to our own lives) and most elusive (because it is not directly observable) of subjects. The organizational settings that interest us complexify our studies, but introduce a social context of vast and growing importance. Three of the four papers found in this volume extol the virtues of dialogue as a source of cognitive change. It's a useful focus for those who study organizational cognition as well. Dialogue can challenge our egocentricity, reveal more of what the situated individual cannot see.

We might learn from the many conversations about global enterprise that 'glocal' (Gustavwson et al., 1994) attention is needed. On the one hand we will benefit from engaging in a global conversation united by a common interest in the way cognition works in organizational contexts. On the other hand, local 
conversations about particular contexts and specific issues are needed. The papers in this volume represent an expanding conversation about organizational cognition in the UK, Europe and other places. They begin to establish the 'multilectic' (Huff, 1978) dialogue required. Our conversation should be wideranging, invigorating, civil, surprising, contradictory and challenging. A central feature of successful exchange, in my mind, is that we continue to be interested in cognitive issues, without becoming distracted by the substantive interests to which we are applying this perspective. It is interesting and important work we are doing together.

Thus it is easy to return to my initial enthusiasm for this particular set of papers and more broadly to my confidence in the future of cognitive studies. These are exciting times. Work like this is considerably expanding our ability to understand and influence the human capacity to achieve desired outcomes.

\section{REFERENCES}

GoFrMAN, E. (1961). Encounters. Indianapolis: Bobbs-Merrill.

Gustavvson, P., Melin, L. and Macdonald, S. (1994). 'Learning to glocalize'. In Shrivastava, P., Huff, A. and Dutton, J. (Eds), Advances in Strategic Management, 10, 255-88.

Hodgkinson, G. P. (1997, this volume). 'Cognitive inertia in a turbulent market: the case of UK residential estate agents'. Journal of Management Studies 34, 6, 921-945.

HuFf, A. (1978). 'Multilectic methods of inquiry'. Human Systems Management, 2, 83-94.

JeNKINS, M. and Johnson, G. (1997, this volume). 'Entrepreneurial intentions and outcomes: a comparative causal mapping study'. Joumal of Management Studies, 34, 6, 895-920.

Leroy, F. and Ramanantsoa, B. (1997, this volume). 'The cognitive and behavioural dimensions of organizational learning in a merger: an empirical study'. Joumal of Management Studies, 34, 6, 871-894.

MinTzBerg, H. (1978). 'Patterns in strategy formation'. Management Science, 24, 9, 934-48.

Paulston, R. G. (1996). Social Cartography: Mapping Ways of Seeing Social and Educational Change. New York: Garland Publishing.

Thomas, A. B. and AL-Maskati, H. (1997, this volume). 'Contextual influences on thinking in organizations: learner and tutor orientations to organizational learning'. Joumal of Management Studies, 34, 6, 851-870.

WALSH, J. P. (1995). 'Managerial and organizational cognition: notes from a trip down memory lane'. Organization Science, 6, 280-321. 
Copyright of Journal of Management Studies is the property of Blackwell Publishing Limited and its content may not be copied or emailed to multiple sites or posted to a listserv without the copyright holder's express written permission. However, users may print, download, or email articles for individual use. 